Research Article

\title{
Experimental Study on Eccentric Compressive Performance of Concrete Column Strengthened with CFRP Grid Reinforced ECC Matrix
}

\author{
Kangjian Lin, ${ }^{1}$ Yuhou Yang, ${ }^{2}$ Zhiwei Chen, ${ }^{3}$ Xiaoyan Sun $\mathbb{D}^{3},{ }^{3}$ and Hailong Wang $\mathbb{D}^{3}$ \\ ${ }^{1}$ Polytechnic Institute, Zhejiang University, Hangzhou 310058, China \\ ${ }^{2}$ Guangxi Transportation Science and Technology Group Co., Ltd., Nanning 530007, China \\ ${ }^{3}$ College of Civil Engineering and Architecture, Zhejiang University, Hangzhou 310058, China
}

Correspondence should be addressed to Hailong Wang; hlwang@zju.edu.cn

Received 13 September 2020; Revised 26 January 2021; Accepted 16 February 2021; Published 27 February 2021

Academic Editor: Pier Paolo Rossi

Copyright (C) 2021 Kangjian Lin et al. This is an open access article distributed under the Creative Commons Attribution License, which permits unrestricted use, distribution, and reproduction in any medium, provided the original work is properly cited.

Carbon-fiber-reinforced polymer (CFRP) grid and engineered cementitious composite (ECC) were combined in this study to strengthen concrete columns. The influences of the number of layers, the overlap length of CFRP grids, and the eccentricity on the bearing capacity and rigidity of reinforced concrete columns were determined. The results show that the principal failure of the reinforced column was debonding of external ECC from FRP grids at the compressive area, edges, or sides. Significant enhancement in the ultimate bearing capacity and rigidity of eccentrically loaded columns was observed after they were externally reinforced by CFRP grids and ECC; such enhancement increased with the number of reinforced layers. Eccentricity made little difference to the enhancement rate of bearing capacity when the number of reinforced layers was the same. At different eccentricities, the composite layers at the tensile area and the compressive area had different contributions to the bearing capacity. An effective bond and efficient stress transfer could be ensured as long as the overlap length between CFRP grids reached $120 \mathrm{~mm}$.

\section{Introduction}

Fiber-reinforced plastic (FRP) has been widely used to strengthen concrete structures due to its numerous advantages, such as light weight, high strength, corrosion resistance, and durability. The most common strengthening method is external bonding of FRP sheets or plates with epoxy adhesive on the concrete members; however, there are still some issues to be addressed, such as aging and poor durability of the adhesive [1]. FRP debonding is the primary cause of failure of concrete structures strengthened by this method. Fabric-reinforced cementitious matrix (FRCM) reinforcement systems not only feature low construction requirements, better flexural-strengthening efficiency, higher cracking loads, and postcracking stiffness [2-5] but also can be bonded using inorganic materials. A variety of FRCM strengthening methods have been developed, including textile reinforced concrete/mortar (TRC/TRM) [6] and FRP grids reinforced cement mortar. When FRP grids are used to reinforce cement mortar, they often slip during the loading process due to insufficient cohesiveness between grids and cement mortar [7]. Furthermore, brittle fracture of cement mortar will occur prior to the failure of FRP grids due to its high brittleness. To increase both the reinforcement efficiency and service life of the structure, an appropriate method should be developed to enable coworking between the cementitious material and FRP grids.

Engineered cementitious composite (ECC) has good penetration resistance and carbonation resistance [8] and shows strong crack control capability and excellent ductility in the presence of an axial tension load [9]. It can provide a protective layer to reinforced concrete (RC) structures that improves their durability if ECC at a thickness of about $20-40 \mathrm{~mm}$ is used in structural strengthening. In addition, ECC can provide effective tensile resistance even at large tensile strain due to the bridging effect of the fibers $[9,10]$, 
which enables it to work cooperatively with FRP grids. There is high bond strength between ECC and FRP [11, 12]; furthermore, ECC embeds in the rectangular holes of FRP grids and covers the grids, which effectively enhances the mechanical interlocking force between them and ensures the synergistic deformation and load-bearing of ECC and FRP grids. There have been some studies on the flexural properties of RC beams strengthened by FRP grids and ECC composite [13-18]; however, few publications have reported the mechanical responses of $\mathrm{RC}$ columns strengthened by this system.

For the above reasons, CFRP grids and ECC were combined to strengthen RC columns in this study. The effectiveness of this strengthening method was examined by determining the influence of the number of layers, overlap length of CFRP grids, and eccentricity on the bearing capacity and rigidity of RC columns. On the basis of the experimental results, the enhancing mechanism of an FRPECC strengthened structure is discussed.

\section{Materials and Test Methods}

2.1. Materials. The cement used for concrete and ECC was a P.O.42.5R ordinary Portland cement that complies with China code GB8076. Local river sand with a fineness modulus of 2.7 was used as the fine aggregate in the concrete, and locally available crushed gravel with a well-grade particle size of $5-31.5 \mathrm{~mm}$ was used as the coarse aggregate. The concrete was mixed using tap water, according to the mixing proportions indicated in Table 1. The designed cubic compressive strength of concrete was $35 \mathrm{MPa}$.

FRP grids were meshed through bidirectional carbon fiber bundles, as shown in Figure 1. Each grid was a square with a spacing of $20 \mathrm{~mm}$. A carbon fiber bundle has a width of $2 \mathrm{~mm}$ and a thickness of $0.044 \mathrm{~mm}$. Its physical properties are shown in Table 2.

The ECC was a composite consisting of the matrix and randomly distributed PVA fiber that served as the reinforcing material in a volume fraction of $2 \%$ [7]. The waterbinder ratio for the matrix was 0.3 . The fine aggregate in the matrix is a type of local fine sand with an average size of $150 \mu \mathrm{m}$. A certain amount of fly ash, silica fume, and metakaolin was also added as the cementitious binder. The ultimate tensile strength and the strain corresponding to the ultimate stress were $3.99 \mathrm{MPa}$ and $2.04 \%$, respectively. The ECC material exhibited a strain-hardening characteristic, and the axial tensile stress-strain relationship can be divided into the following three stages: (1) elastic rising stage, in which the matrix did not crack; the first crack occurred at the end of the elastic stage; (2) strain-hardening stage, which was accompanied by growing strain, slightly rising stress, and steady propagation of cracks. When the first crack occurred but had not run through the specimen, the randomly distributed fiber would play a bridging role and create many microcracks around the first crack [19, 20]; (3) strain softening stage, in which tensile strength dropped slowly after it peaked, and cracks expanded and concentrated, finally resulting in the fracture of the specimen.
TABLE 1: Mixing proportions of concrete.

\begin{tabular}{lccccc}
\hline Material & Cement & Water & Sand & Gravel & Water reducer \\
\hline Amount $\left(\mathrm{kg} / \mathrm{m}^{3}\right)$ & 494 & 158 & 594 & 1149 & 5.0 \\
\hline
\end{tabular}

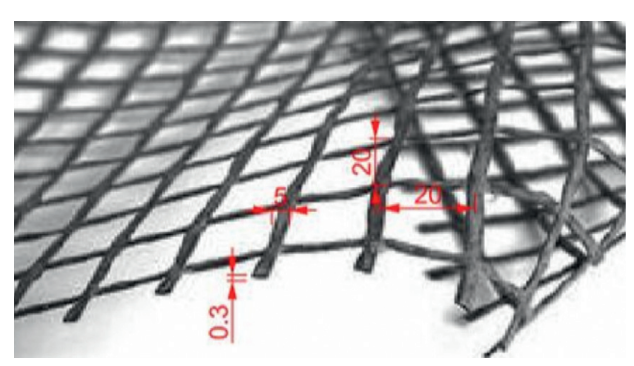

Figure 1: Dimensions of CFRP grid (mm).

2.2. Specimens. Hollow RC columns were used in the test, as shown in Figure 2. The cross section, wall thickness, hollowed part, and total height of each specimen were $240 \mathrm{~mm} \times 240 \mathrm{~mm}, \quad 50 \mathrm{~mm}, \quad 140 \mathrm{~mm} \times 140 \mathrm{~mm}$, and $1600 \mathrm{~mm}$, respectively. Steel bars with a yield strength of $400 \mathrm{MPa}$ were used in the eccentrically loaded columns. Sixteen longitudinal bars with a diameter of $10 \mathrm{~mm}$ were evenly distributed around the column wall, and stirrups with a diameter of $8 \mathrm{~mm}$ were arranged at a spacing of $150 \mathrm{~mm}$. To ensure the bearing capacity of the bracket, four longitudinal bars with a diameter of $10 \mathrm{~mm}$ in the hollow column were curved into the bracket as longitudinal bars. In addition, three longitudinal bars with a diameter of $24 \mathrm{~mm}$ were placed in the bracket, stretching $150 \mathrm{~mm}$ into the column along the outer edge of the bracket. Stirrups were also more densely arranged, at a spacing of $80 \mathrm{~mm}$, in the bracket (Figure 2).

The eccentrically loaded concrete columns were externally strengthened with CFRP grids and ECC. Three control specimens and seven strengthened specimens were prepared in the test to determine the influence of overlap length, number of CFRP grid layers, and eccentricity on the bearing capacity and rigidity of the RC structure. The information of the specimen is summarized in Table 3.

All specimens were cast in wooden formworks. The specimens were demolded after $24 \mathrm{~h}$ and were wet cured in ambient conditions for one month before they were strengthened. During strengthening, the edges on the column were chamfered at a radius of $20 \mathrm{~mm}$. The four sides of the column body were roughened to increase the bond strength between strengthening materials and concrete. Then, a layer of ECC with a thickness of $5 \mathrm{~mm}$ was applied to the cleaned surface of the column, followed by FRP grids on the surface of the ECC. A certain overlap length was reserved as per the designed parameter. Finally, another layer of ECC with the same thickness was plastered on the surface of FRP grids. The total strengthening thicknesses of specimens with two and three FRP grid layers were $15 \mathrm{~mm}$ and $20 \mathrm{~mm}$, respectively. Specimens were wet cured for 28 days after strengthening. 
Table 2: Physical properties of FRP.

\begin{tabular}{lcccc}
\hline Fiber type & $\begin{array}{c}\text { Designed tensile strength } \\
(\mathrm{kN} / \mathrm{m})\end{array}$ & $\begin{array}{c}\text { Ultimate load of a single fiber } \\
\text { bundle }(\mathrm{kN})\end{array}$ & $\begin{array}{c}\text { Elastic modulus of fiber } \\
(\mathrm{GPa})\end{array}$ & $\begin{array}{c}\text { Ultimate tensile stress at the strain of } \\
1.75 \%(\mathrm{kN} / \mathrm{m})\end{array}$ \\
\hline $\begin{array}{l}\text { Carbon } \\
\text { fiber }\end{array}$ & 101.2 & 3.2 & 230 & 200 \\
\hline
\end{tabular}

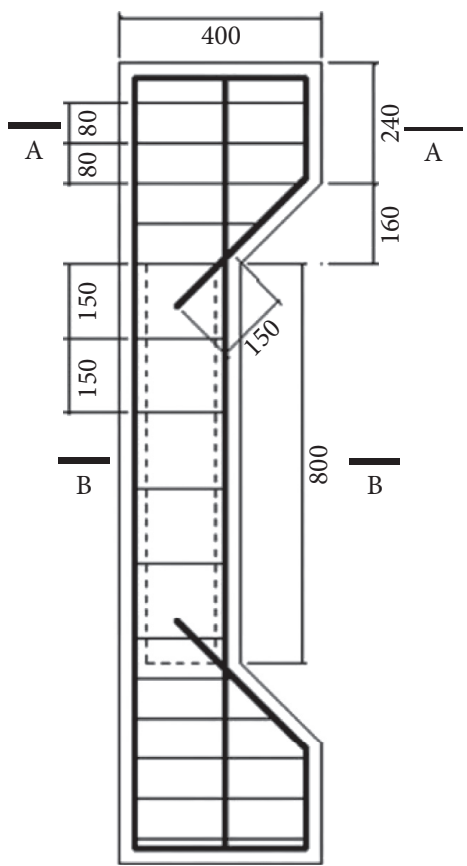

(a)

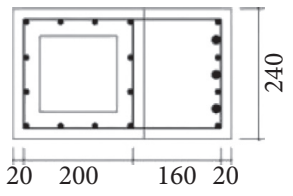

$\underline{\mathrm{A}-\mathrm{A}}$

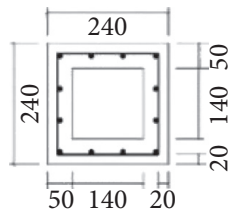

$\underline{\mathrm{B}-\mathrm{B}}$

(b)

(c)

Figure 2: Dimensions of specimens. (a) Hollow column. (b) Bracket reinforcement. (c) Column body reinforcement.

TABle 3: Summary of tested specimens.

\begin{tabular}{|c|c|c|c|c|}
\hline Influencing factors & Specimen ID & Number of grid layers & Eccentricity (mm) & Overlap length $(\mathrm{mm})$ \\
\hline \multirow{3}{*}{ Control group (unstrengthened) } & P-L0-e1 & - - & 90 & - - \\
\hline & P-L0-e2 & - & 140 & -- \\
\hline & $\mathrm{P}-\mathrm{L} 0-\mathrm{e} 3$ & - & 220 & - \\
\hline \multirow{3}{*}{ Strengthened group (number of grid layers) } & S-L1-e2 & 1 & 140 & 240 \\
\hline & S-L2-e2 & 2 & 140 & 240 \\
\hline & S-L3-e2 & 3 & 140 & 240 \\
\hline \multirow{2}{*}{ Strengthened group (eccentricity) } & S-L2-e1 & 2 & 90 & 240 \\
\hline & S-L2-e3 & 2 & 220 & 240 \\
\hline \multirow{2}{*}{ Strengthened group (overlap length) } & S-L2-e2-S & 2 & 140 & 120 \\
\hline & S-L2-e2-M & 2 & 140 & 480 \\
\hline
\end{tabular}

Note. P, S, and L represent the unstrengthened group, strengthened group, and number of grid layers, respectively. e1, e2, and e3 are increasing eccentricities. $\mathrm{M}$ and $\mathrm{S}$ in the row of overlap length denote overlap lengths of $480 \mathrm{~mm}$ and $120 \mathrm{~mm}$, respectively; the overlap lengths in the rest of the columns are $240 \mathrm{~mm}$.

2.3. Methodology. All tests were performed using a YAW10000F electrohydraulic servo testing machine developed by Zhejiang University. As shown in Figure 3(a), there was a spherical hinged support at the loading end of the testing machine; a cutter hinged support was placed at the lower support of the column to control the eccentricity of loading. The locations of the concrete strain gauges and dial indicators are shown in Figure 3(b). Concrete strain gauges were placed on the lateral side, and on the compressive and tensile areas of each column. Concrete strain and steel bar strain were collected using a static strain measurement system. A DJCK intelligent crack detector was used to observe the cracks throughout the test, which was carried out following the Standard for Test Method of Concrete Structures (GB50252-92). Monotonic multistage loading was applied at the beginning, with every increment not exceeding $10 \%$ of 


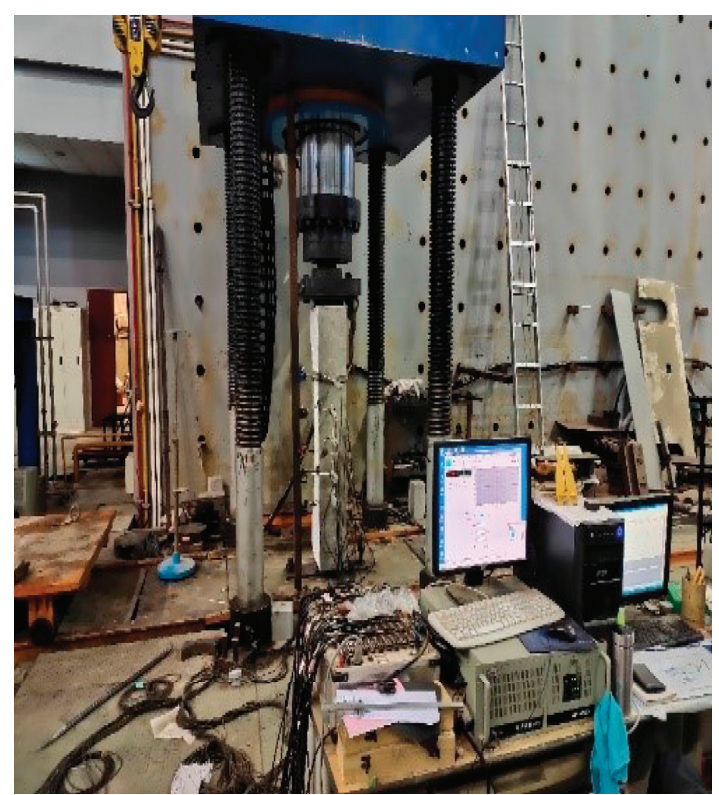

(a)

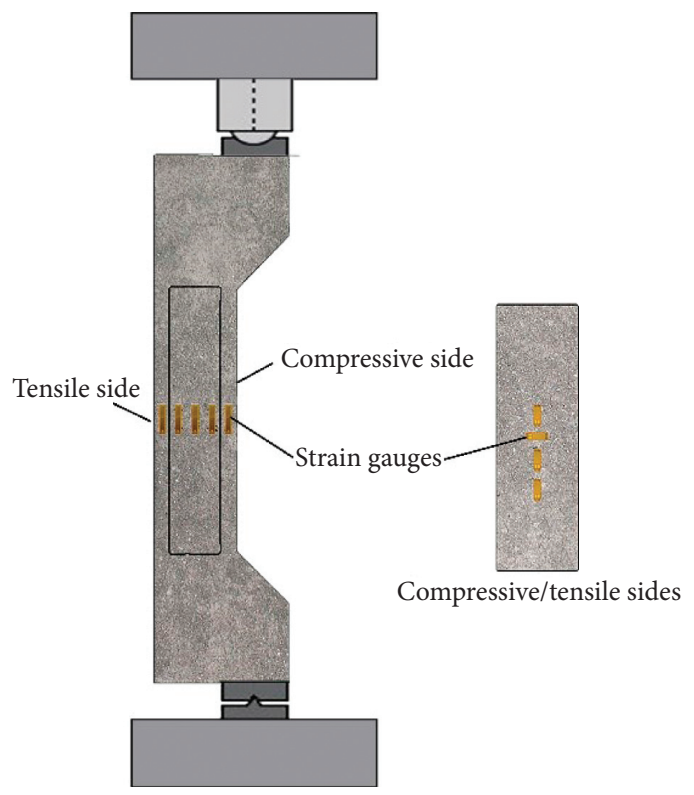

(b)

Figure 3: Testing and locations of measuring points. (a) Testing device. (b) Locations of concrete strain gauges.

ultimate load. When the load was approaching peak load, displacement loading was applied at a rate of $0.2 \mathrm{~mm} / \mathrm{min}$.

\section{Results and Discussion}

3.1. Failure Pattern. Unstrengthened hollow columns failed in the same way as typical RC columns under eccentric loading. Transverse cracks occurred at the tensile area and vertical cracks appeared at the compressive area, both of which expanded with the increase of the applied load. Finally, concrete crushing failure was observed at the compressive area, and the eccentrically loaded columns failed.

Strengthened columns showed the same deformation trend as control columns at the beginning of loading. With the increase of load, transverse cracks occurred at the tensile area; the concrete at the compressive area expanded laterally, activating the FRP grid-ECC system to provide lateral confinement. The FRP grid-ECC composite reinforcing layer bore increasingly higher pressure and tension as the load increased. Finally, the external ECC was stripped from the FRP grids, which caused a decline in the rigidity of the composite layer and the drop of bearing capacity of the structure. The typical failure patterns are displayed in Figure 4.

3.2. Results. Test results are listed in Table 4. Initial lateral rigidity was obtained using the equation of material mechanics based on the measured deflection. As shown in Table 4, the ultimate strength of the columns and their lateral rigidities improved significantly after the CFRP grid-ECC system was used to strengthen the columns. The ultimate bearing capacity and the lateral rigidity of strengthened columns increased with the increasing number of grid layers. At different eccentricities, there was no significant difference in the compressive strength enhancement rate, and the enchantment was about $27 \%$ when the columns were strengthened by two composite layers. Overlap length made little difference to the bearing capacity and rigidity of reinforced columns.

3.3. Influence of the Number of Grid Layers. The load-lateral deflection curves of RC columns strengthened with different grid layers and ECC composite at the same eccentricity are shown in Figure 5. It can be seen that the peak load and rigidity of the columns increased with the number of grid layers. Two major factors can explain the bearing capacity enhancement: (1) tensile strain occurred at the tensile area of the column under eccentric load, causing the FRP grid-ECC composite layer to provide a tensile resistance [21]. In addition, compared with the unstrengthened column, the growing tensile force increased the section height at the compressive area. (2) Since all the columns failed as concrete crushing at the compressive area, the compressive strength of concrete is critical to the capacity of an RC column. The externally coated FRP grid-ECC composite layer can provide lateral confinement to the concrete at the compressive area. When the concrete strain at the compressive area reached a certain level, this lateral confinement would be activated $[22,23]$. As a result, the core concrete was subjected to a three-directional stress state, and its compressive property was significantly improved, $[24,25]$ thereby increasing the bearing capacity of a column.

The cross-sectional strain and stress distributions of strengthened RC columns are shown in Figure 6. The initial lateral rigidity of the section was impacted by the position of the neutral axis and the material property of the section. When columns were strengthened by FRP grid-ECC composite, the position of the neutral axis would be shifted. The 

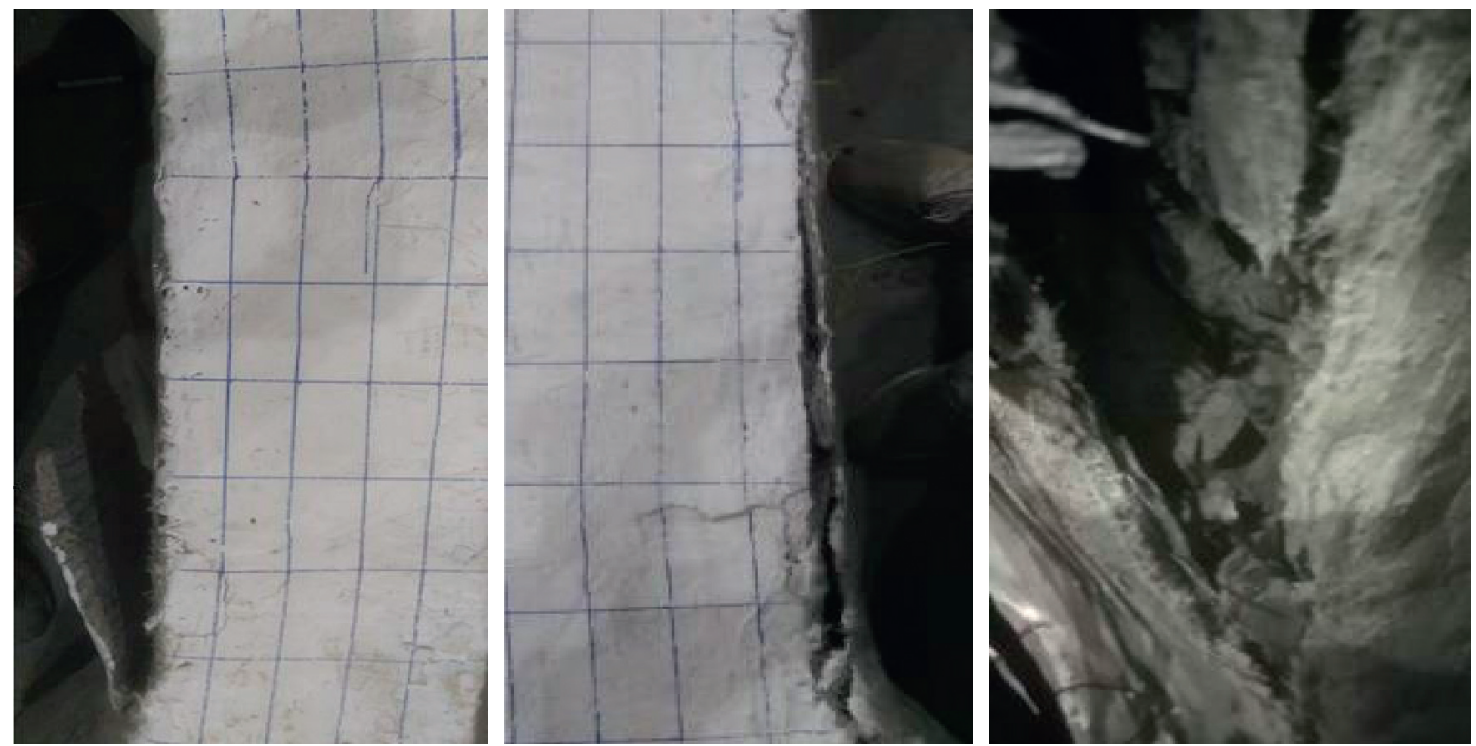

Figure 4: Typical failure pattern.

TABLE 4: Test results.

\begin{tabular}{|c|c|c|c|c|c|}
\hline Specimen ID & Peak load $P_{\mathrm{cr}}(\mathrm{kN})$ & Compressive strength enhancement (\%) & $\begin{array}{c}\text { Lateral deflection } \\
\text { corresponding to } P_{\mathrm{cr}} \\
(\mathrm{mm})\end{array}$ & $\begin{array}{l}\text { Initial lateral } \\
\text { rigidity } \\
\left(\mathrm{kN} \cdot \mathrm{mm}^{2}\right)\end{array}$ & $\begin{array}{c}\text { Lateral rigidity } \\
\text { enhancement }(\%)\end{array}$ \\
\hline P-L0-e1 & 610 & - & 7.25 & 2.22 & - \\
\hline P-L0-e2 & 380 & - & 8.75 & 2.65 & - \\
\hline P-L0-e3 & 263 & - & 13.35 & 1.57 & - \\
\hline S-L1-e2 & 440 & 15.8 & 12.05 & 1.68 & - \\
\hline S-L2-e2 & 483 & 27.1 & 8.31 & 3.23 & 21.9 \\
\hline S-L3-e2 & 528 & 38.9 & 9.76 & 3.33 & 25.7 \\
\hline S-L2-e1 & 794 & 30.2 & 4.74 & 6.98 & 214.4 \\
\hline S-L2-e3 & 340 & 29.3 & 9.67 & 3.73 & 148.7 \\
\hline S-L2-e2-S & 469 & 23.4 & 9.78 & 3.19 & 20.4 \\
\hline S-L2-e2-M & 505 & 32.9 & 12.37 & 3.38 & 27.5 \\
\hline
\end{tabular}

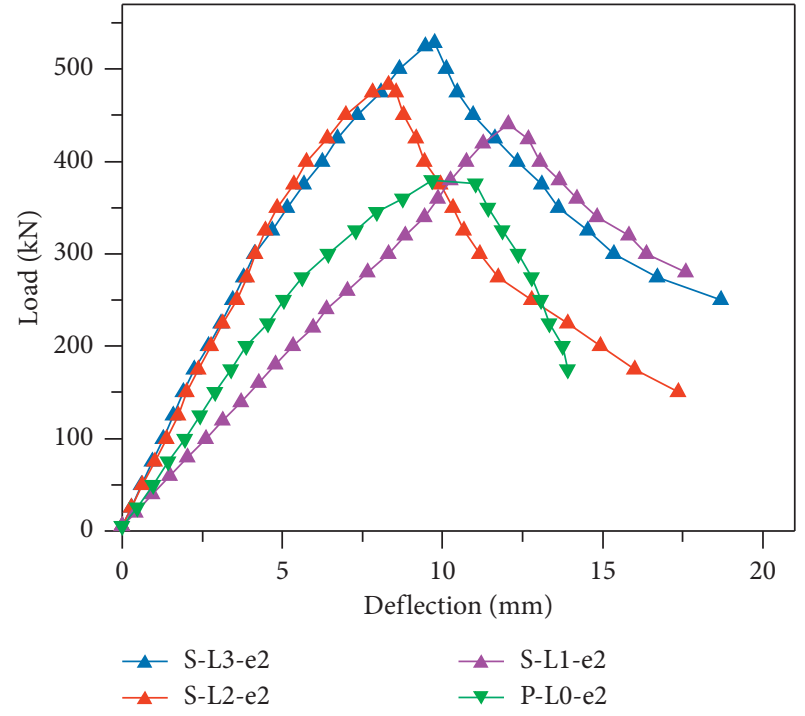

Figure 5: Load-lateral deflection curves of eccentrically loaded columns with different grid layers.
FRP grid-ECC layer at the tensile area could be simplified as longitudinal bars. Both the increased reinforcement ratio and compressive property improvement of the confined concrete at the compressive area had an influence on the lateral rigidity of the strengthened column, which can be written as

$$
E^{\prime} I^{\prime}=\frac{b x_{c}^{3}}{12} E_{C}^{\prime}+\left(h-x_{c}\right)^{2} T,
$$

where $E_{C}^{\prime}, T$, and $x_{c}$ are the elasticity modulus of the confined concrete, the tensile force provided by the tensile side, and the height of the compressive area, respectively. The sectional rigidity corresponding to the elasticity moduli of the confined concrete, the steel bars at the tensile area, and the FRP grid-ECC composite layer can be determined by obtaining the height $\left(x_{c}\right)$ of the compressive area.

The derivative of sectional rigidity with respect to $x_{c}$ is

$$
\frac{\mathrm{d} E^{\prime} I^{\prime}}{\mathrm{d} x_{c}}=\frac{\mathrm{bx}_{c}^{2}}{4} E_{C}^{\prime}-2\left(h-x_{c}\right) T^{\prime} \text {. }
$$




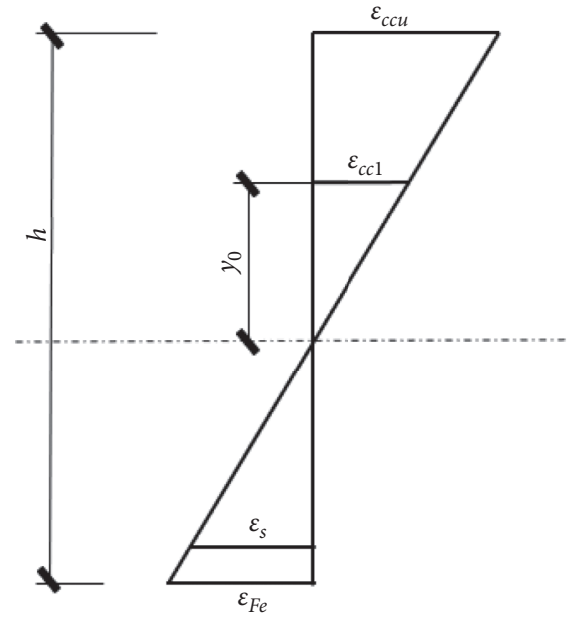

(a)

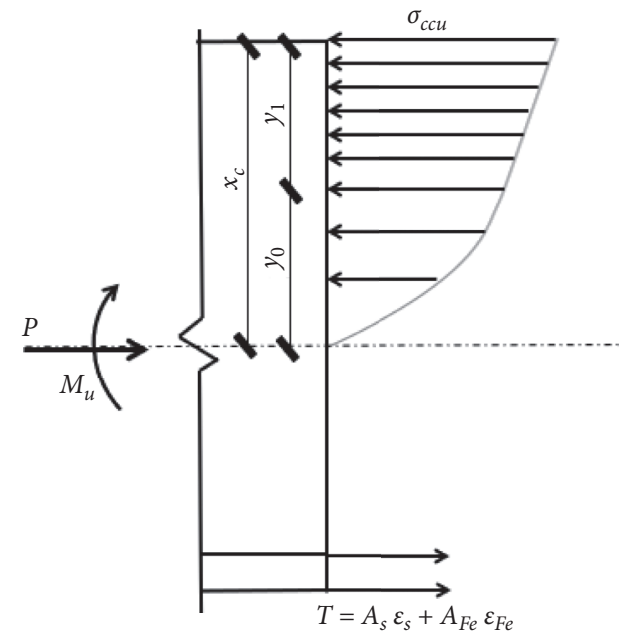

(b)

FIgURE 6: Cross-sectional strain and stress distribution.

$E^{\prime} I^{\prime}$ is smallest when $\mathrm{d} E^{\prime} I^{\prime} / \mathrm{d} x_{c}=0$ for the eccentrically loaded column, where $0.5 h<x_{c}<h$. It can be seen from the test results in Table 4 that when the number of grid layers was the same, the sectional rigidity at the eccentricity of $140 \mathrm{~mm}$ was smaller than that at eccentricities of both $90 \mathrm{~mm}$ and $200 \mathrm{~mm}$. In other words, section rigidity showed a decreasing-increasing trend with the increase of eccentricity. According to the relationship between lateral rigidity and the height of the compressive area shown above, the section rigidity at the eccentricity of $140 \mathrm{~mm}$ was close to the minimum value. Therefore, the sectional rigidity of the reinforced column was enhanced only by about $25 \%$.

3.4. Influence of Eccentricity. The load-lateral deflection curves of strengthened and unstrengthened columns at different eccentricities are shown in Figure 7. For the column with small eccentricity, the ultimate bearing capacity increased by $30 \%$ to $794 \mathrm{kN}$ after strengthening; the lateral deflection at the ultimate bearing capacity was $4.74 \mathrm{~mm}$, and the initial lateral rigidity improved by $214.4 \%$. By contrast, the ultimate bearing capacity of the column with large eccentricity increased by $29.3 \%$ to $340 \mathrm{kN}$ after strengthening; the lateral deflection at the ultimate bearing capacity was $13.35 \mathrm{~mm}$, and the initial lateral rigidity improved by $148.7 \%$. It can thus be inferred that this strengthening method showed a significant effect on the lateral rigidity of both types of columns. The same strengthening method had a roughly equivalent effect on the bearing capacity of columns at different eccentricities.

When the column subjected to small eccentric compression reached its ultimate strength, the maximum tensile strain of ECC was $768.2 \mu \varepsilon$. At this point, the FRP grid-ECC composite layer at the tensile area showed a low utilization ratio, the compressive area was high, and the lateral confinement provided by the FRP grid-ECC composite layer at the compressive area contributed

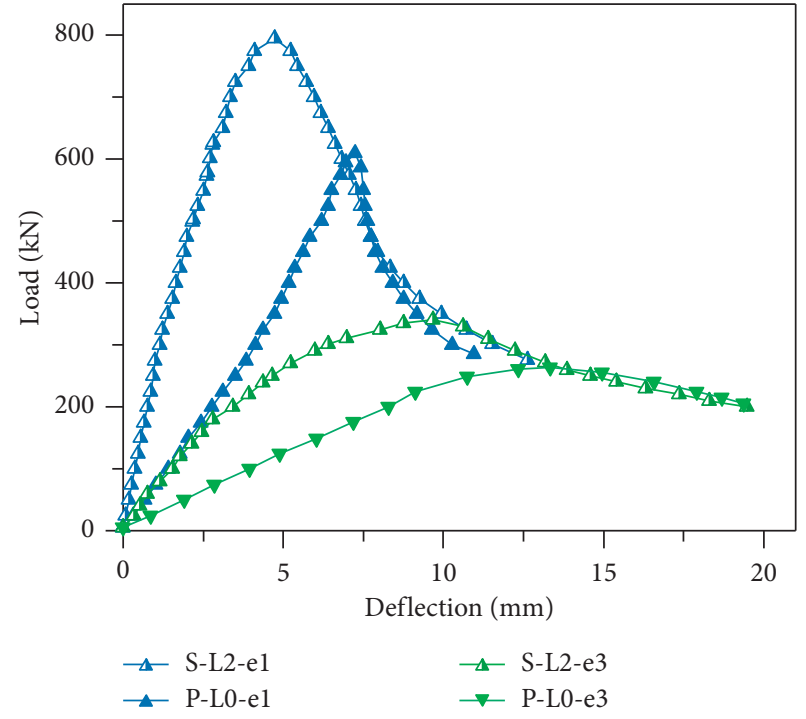

Figure 7: Load-lateral deflection curves of strengthened and unstrengthened columns with different eccentricities.

greatly to bearing capacity enhancement. However, the maximum tensile strain at the tensile area reached 5881 $\mu \varepsilon$ when the column subjected to large eccentric compression reached its ultimate strength. The composite layer at the tensile area showed a high utilization ratio; however, the compressive area was lower, and the lateral confinement provided by the composite layer at the compressive area contributed less to the enhancement of bearing capacity. Thus it can be seen that although the tension provided by the FRP grid-ECC composite layer at the tensile area and the lateral confinement by the composite layer at the compressive area made different degrees of contribution to the enhancement of column bearing capacity at different eccentricities, their overall contribution is roughly the same. 


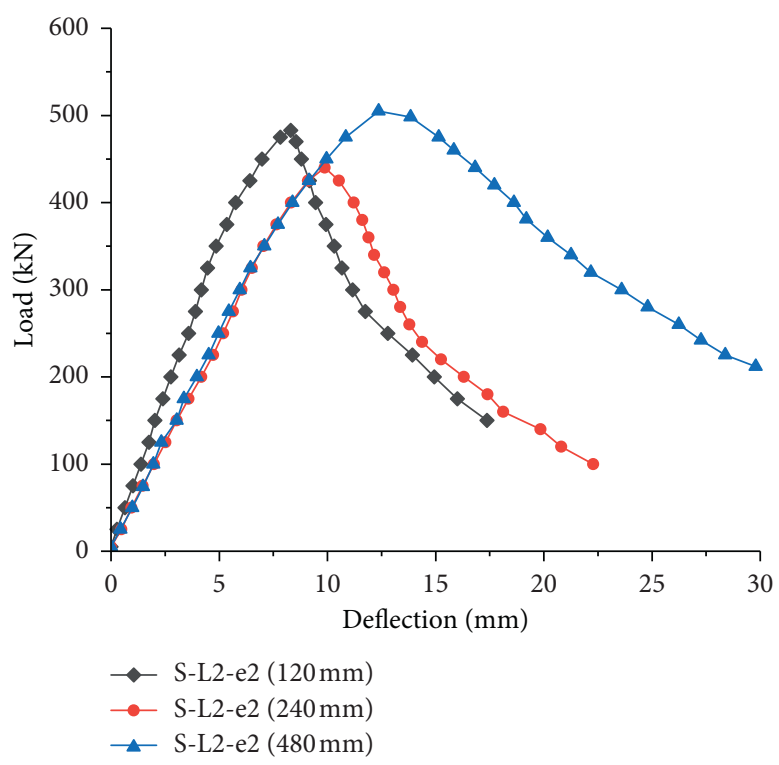

(a)

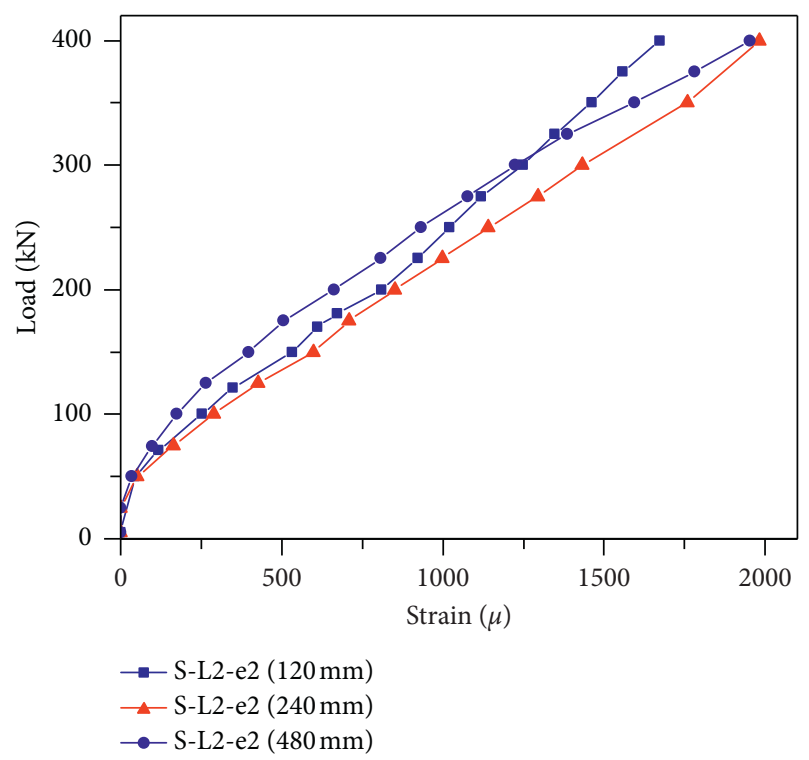

(b)

FIGURE 8: Load-strain responses of eccentrically loaded columns with different overlap lengths. (a) Load-lateral deflection curves of eccentrically loaded columns at different overlap lengths. (b) Load-maximum compressive strain curves of concrete at different overlap lengths.

3.5. Influence of Overlap Length. The synergistic deformation of FRP grids and ECC depends mainly on the bond strength and mechanical interlocking force between them. ECC and FRP themselves have excellent bond performance. In this test, the rectangular frames of FRP grids were $20 \mathrm{~mm} \times 20 \mathrm{~mm}$ in size. Due to the interlocking force of ECC in the rectangular holes between FRP grids and its coverage on the grids, the mechanical interlocking force between FRP and ECC was enhanced [7]. This ensured synergistic deformation between them. At different overlap lengths, the ultimate bearing capacities of eccentrically loaded columns differed less than $8 \%$; the load-lateral deflection curve and load-maximum strain curve of the column basically coincided in the linear elastic stage (Figure 8). It can thus be concluded that the strengthening method is effective and the load can be efficiently transferred between structural materials as long as the overlap length reaches $120 \mathrm{~mm}$.

\section{Conclusions}

When an eccentrically loaded column was strengthened with FRP grid-ECC composite layers, the principal failure mode of an RC column was debonding of external ECC from CFRP grids at the compressive area, sides, or edges. CFRP grids did not break and were well bonded within the inner ECC layer. Material utilization can be enhanced by properly increasing the thickness of the inner ECC layer and reducing that of the outer ECC layer.

The bearing capacity and structural rigidity of an RC column increased with the increasing number of strengthened grid layers. The ultimate bearing capacity of columns with one, two, and three layers of CFRP grids was improved by $15.8 \%, 27.1 \%$, and $38.9 \%$, respectively. The lateral rigidity of a strengthened column was significantly enhanced when an FRP grid-ECC composite system was used in the reinforcement.

Eccentricity makes little difference to the enhancement of ultimate bearing capacity of the strengthened column. At different eccentricities, the tension provided by the FRP grid-ECC composite layer at the tensile area and the lateral confinement by the composite layer at the compressive layer made different degrees of contribution to the bearing capacity enhancement of columns when strengthened in the same way. Nevertheless, their overall contribution to the mechanical response was roughly the same.

ECC and FRP grids can be effectively bonded. The reinforcement is effective and the load can be efficiently transferred between structural materials as long as the overlap length reaches $120 \mathrm{~mm}$.

\section{Data Availability}

The data used to support the findings of this study are available from the corresponding author upon request.

\section{Conflicts of Interest}

The authors declare that they have no conflicts of interest regarding the publication of this paper.

\section{Acknowledgments}

This study was supported by the National Natural Science Foundation of China (no. 52079123), the Key Research and Development Project of Zhejiang Province (no. 2021C01022), the Guangxi Key Research and Development Project (no. AB17292062), and the Production and 
Construction Group's Programs for Science and Technology Development (no. 2019AB016).

\section{References}

[1] T. C. Triantafillou and N. Plevris, "Strengthening of RC beams with epoxy-bonded fibere-composite materigals," Materials and Structure, vol. 25, no. 148, pp. 201-211, 1992.

[2] Z. Q. Liu, Q. R. Yue, and Y. Ding, "FRP grid in civil engineering applications," in Proceedings of the 9th National Conference on FRP Application Civil Engineering, pp. 111-115, Chongqing, China, 2015, in Chinese.

[3] S. Babaeidarabad, G. Loreto, and A. Nanni, "Flexural strengthening of RC Beams with an externally bonded fabricreinforced cementitious matrix," Journal of Composites for Construction, vol. 18, no. 5, Article ID 4014009, 2014.

[4] W.-Y. Gao, K.-X. Hu, J.-G. Dai, K. Dong, K.-Q. Yu, and L.-J. Fang, "Repair of fire-damaged RC slabs with basalt fabric-reinforced shotcrete," Construction and Building Materials, vol. 185, no. 10, pp. 79-92, 2018.

[5] J. G. Dai, S. Munir, and Z. Ding, "Comparative study of different cement-based inorganic pastes towards the development of FRIP strengthening technology," Journal of Composites for Construction, vol. 18, no. 3, Article ID A4013011, 2014.

[6] A. Brückner, R. Ortlepp, and M. Curbach, "Textile reinforced concrete for strengthening in bending and shear," Materials and Structures, vol. 39, no. 8, pp. 741-748, 2006.

[7] X. C. Yan, X. Z. Weng, Y. N. Kou, L. Liang, and G. X. Zhang, "Bending mechanical properties of cement concrete with fiber grid reinforcement," Journal of Southwest Jiaotong University, vol. 47, no. 3, pp. 394-399, 2012, in Chinese.

[8] Z. Jia, B. Jiang, G. X. Cheng, and X. B. Yang, "Research progress of fibers reinforced cement based composites," Concrete, vol. 214 , no. 8, pp. 65-68, 2007, in Chinese.

[9] V. C. Li, "Tensile strain-hardening behavior of polyvinyl alcohol engineered cementitious composite," Aci Materials Journal, vol. 98, pp. 483-492, 2001.

[10] S. L. Gao, Study on Pseudo Strain-Hardening and Fracture Characteristic of Polyvinyl Alcohol Fiver Reinforced Cementitious Composites, Dalian University of Technology, Dalian, China, 2006, in Chinese.

[11] E. Franzoni, C. Gentilini, M. Santandrea, and C. Carloni, "Effects of rising damp and salt crystallization cycles in FRCM-masonry interfacial debonding: towards an accelerated laboratory test method," Construction and Building Materials, vol. 175, pp. 225-238, 2018.

[12] T. Fang, Mechanical Properties of FRP Bar-ECC-Concrete Composite Structures, Zhejiang University, Hangzhou, China, 2015.

[13] X. Yang, W. Y. Gao, J. G. Dai, and Z. D. Lu, "Shear strengthening of RC beams with FRP grid-reinforced ECC matrix," Composite Structures, vol. 241, Article ID 112120, 2020.

[14] Y. Z. Zheng, W. W. Wang, K. M. Mosalam, Q. Fang, L. Chen, and Z. F. Zhu, "Experimental investigation and numerical analysis of RC beams shear strengthened with FRP/ECC composite layer," Composite Structures, vol. 246, Article ID 112436, 2020.

[15] X. Yang, W.-Y. Gao, J.-G. Dai, Z.-D. Lu, and K.-Q. Yu, "Flexural strengthening of RC beams with CFRP grid-reinforced ECC matrix," Composite Structures, vol. 189, pp. 9-26, 2018.
[16] R. Guo, W. H. Hu, M. Q. Li, and B. Wang, "Study on the flexural strengthening effect of RC beams reinforced by FRP grid with PCM shotcrete," Composite Structures, vol. 239, Article ID 112000, 2020.

[17] B. Wang, Z. Wang, K. Uji, J. Zhang, and R. Guo, "Experimental investigation on shear behavior of RC beams strengthened by CFRP grids and PCM," Structures, vol. 27, pp. 1994-2010, 2020.

[18] Y.-Z. Zheng, W.-W. Wang, and J. C. Brigham, "Flexural behaviour of reinforced concrete beams strengthened with a composite reinforcement layer: BFRP grid and ECC," Construction and Building Materials, vol. 115, pp. 424-437, 2016.

[19] H. L. Wang, Y. J. Luo, G. Y. Peng, X. Y. Sun, and Q. M. Ying, "Effect of admixtures on tensile behavior of fiber reinforced cementitious composites," Journal of Southwest Jiaotong University, vol. 52, no. 1, pp. 61-68, 2017, in Chinese.

[20] C. X. Gong and J. Zhang, "Tensile performance of high ductile fiber reinforced cementitious composite," Journal of $\mathrm{Hy}$ draulic Engineering, no. 3, pp. 361-366, 2008, in Chinese.

[21] Q. L. Xian, W. J. Yi, and H. T. Ding, "Experiment and research of reinforced concrete column externally bonded with CFRP sheets under eccentric load," Industrial Construction, no. 11, pp. 78-81, 2004, in Chinese.

[22] Y. P. Li, Experimental Investigation and Theoretical Analysis for Performance of Concrete Columns Confined with Carbon Fiber Composite Sheets, Tongji University, Shanghai, China, 2006.

[23] S. Y. Cao, D. H. Jin, and N. Sun, "Behaviors of concrete columns strengthened by CFRP sheets under eccentric compression," China Civil Engineering Journal, no. 8, pp. 26-32+37, 2006, in Chinese.

[24] L. Lam and J. G. Teng, "Compressive strength of FRP-confined concrete in rectangular columes," in Proceedings of the Frp Composites in Civil Engineering International Conference on Frp Composites in Civil Engineering, Hong Kong, China, December 2001.

[25] M. N. S. Hadi, "Behaviour of FRP wrapped normal strength concrete columns under eccentric loading," Composite Structures, vol. 72, no. 4, pp. 503-511, 2006. 